\title{
Research on the Practical Teaching System of Agricultural Water Conservancy Engineering Talents Cultivation
}

\author{
Cheng $\mathrm{Yao}^{1}$, Ni Fuquan* ${ }^{2}$, Lu Xiuyuan ${ }^{2}$, Yang $\mathrm{Min}^{2}$ \\ ${ }^{1}$ Teaching Affairs Section of Sichuan Agricultural University Ya'an Sichuan China \\ ${ }^{2}$ College of Information Engineering and Technology of Sichuan Agricultural University \\ Ya'an Sichuan China \\ email: nfq1965@163.com(Corresponding author)
}

\begin{abstract}
Keywords: Agricultural Water Conservancy Talents; Practical Teaching System; Construction; Effect; Quality Control
\end{abstract}

\begin{abstract}
Based on the historical opportunities and great challenges of water resources and hydropower resources development and utilization in Ya'an city of Sichuan province, together with the public experiment teaching platform, practical teaching base, practical teaching management and quality control mode, this paper combined the local characteristics and water conservancy features of the Minjiang River basin, especially those of the seven counties and one district in Ya'an, constructed and implemented the practical teaching system of agricultural water conservancy engineering.
\end{abstract}

\section{Introduction}

In order to cultivate interdisciplinary talents of high qualities with solid basic theory, engineering consciousness, innovation spirit and strong practical abilities, it is of great significance to implement multidisciplinary crossing field of water conservancy teaching by making full use of the geographical advantages of Sichuan Agricultural University and regarding field of water conservancy practice in Minjiang River system as the starting point, and so as to achieve mastery through a comprehensive study of different courses in water conservancy majors, to perfect the knowledge structure at undergraduate stage, and to realize implementation of engineering as well as freestyle education. It is very important to construct and implement the practice teaching system for agricultural water conservancy professionals' cultivation. The study on this project should, with scientific outlook on development as the fingerpost and social demand as the guide, be carried out through in-depth research on the new requirements which are put forward by economic society, science and technology, and culture development on higher education of agricultural water conservancy professionals, and unite the relevant administrative departments, industry associations or other societies. Meanwhile, this research needs to be conducted by widely absorbing opinions and suggestions from all aspects such as schools, different industries, employing units etc, and seek for close connection with the professional services orientation and the industry requirements in development with quality education and innovation education concept as the guide. Besides, it is preferable to insist on the principle of coordinated development of knowledge, ability and quality and conduct this research in accordance with the general requirement of "solid foundation, wide span of knowledge, strong abilities and high qualities”.

\section{Construction on Practical Teaching System for Professionals Cultivation}

At present, the main problems of education on water conservancy engineering major are characterized by a narrow range, single knowledge structure; obsolete teaching content, rigid teaching methods. Based on the background, construction research of practical teaching system is to be conducted as follows: First of all, it is important to take ability training as the main line and is thus necessary to start with knowledge structure, practical ability, innovation ability and innovation education so that a hierarchical, multi-module, open, features-valued and well-converged practical teaching system can be built up to comprehensively integrate and reconstruct the practical curriculum. Secondly, the basic content of practical teaching should be updated and courses are to be 
arranged according to the order of "basic-comprehensive-innovative", so that various types of practical courses at different levels could be set up. It follows that the practical teaching system of agricultural water conservancy engineering major can be divided into 4 levels, namely, basic skills, professional skills, comprehensive skills and innovation skills. The 4 levels that range from basic to comprehensive can make knowledge, capacity and quality organically connected and integrated with each other. On the basis of this, the main course system can then fall into seven modules, that is, the basic experiment module, hydraulic experimental module, hydraulic structure experiment module, module of irrigation and drainage engineering, water conservancy project construction module, field practical module and scientific research training modules.

\section{The Implementation of the Practical Teaching System of Professionals Cultivation}

\section{Revision of the Experimental Teaching Syllabus}

Firstly, special workshops need to be conducted, and experts inside and outside school shall be invited to participate in educational reform seminars. Secondly, the experimental types can be divided into: basic courses, specialized courses, core curriculum and integrated design. Repeated experimental content could be avoided by transforming the simple skills cultivation into comprehensive and integrated ability training, students' understanding of inner organic connection of interdisciplinary could thus be strengthened. The teaching approach is divided into: compulsory experiment, selective experiment, open experiment, exploratory experiment. A loose and free study atmosphere should be created to strengthen the cultivation of students' professional interest. The assisting method is divided into: simulation demonstration, electronic teaching plan, computer data processing. And all the core courses and experiments should be vividly and visually presented to students.

\section{Integration of Practical Teaching, Scientific Research, Project and Social Practice}

For the purpose of training talents of high level, the innovative talents training mode should be vigorously explored and practical teaching system of agricultural water conservancy engineering major should also be adjusted and constructed, as it is particularly urgent to develop a free and engineering consciousness. According to research results obtained presently, the current situation of practice base and the teaching achievements over the years, field practice instruction book of high quality should be compiled to strengthen the auxiliary teaching means such as multimedia, video and online teaching. Meanwhile, the optimized practice time and teaching content shall be earnestly arranged in terms of point, line and facet. It is also necessary to constantly optimize and design the network system of field practice for agricultural water conservancy major so as to meet the needs of being compact, time saving, work saving and money saving in network system. The following practical lines have been designed:

1) Routes of Daxing hydropower station, Yu Cheng power stations, and Duo Yingping hydrometric station, mainly for the course of Engineering Hydrology, etc.;

2) Routes of the town of Fei Xianguan estuary physiognomy and attitude of rocks measurement, Zhou Gong mountain hot springs in Liba village of Yu Cheng District, Ya'an gorge hazard monitoring demonstration area, Diaobao mountain hazard geology scene in Beijiao village of $\mathrm{Yu}$ Cheng district, mainly for the course of Engineering Geology and Hydrological Geology, Soil Mechanics etc;

3) Routes of school farm, Dujiangyan irrigation area, Minshan irrigation area, mainly for the course of Irrigation and Drainage Engineering, Irrigation and Water Conservancy etc;

4)Routes of Zipingpu hydropower station, Longxin hydropower station, Guidufu hydropower station, Shuijinguan hydropower station, Xiacun hydropower station, Caoyutan hydropower station, Dashiban hydropower station, mainly for the course of Hydraulic Structure, Water Pump and Water Pump Station, Reinforced Concrete and Masonry Structure, Water Conservancy Mapping, Engineering Surveying, Social Practice and so on;

5)For the course of Water Conservancy Project Construction and Supervision, Graduation Practice etc, Pubugou hydropower station is now building hydropower station practice outline and the practice guidance. 
Practice bases have been set up with surrounding areas of school such as medium-sized hydropower station, water conservancy and hydropower engineering investigation design and research institute, construction and management units of the irrigation project and so on. Cooperation agreements were jointly established by two sides and relevant management system were formed and gradually improved. Meanwhile, a multi-level practical teaching faculty with special and minor combination and reasonable structure has been built up. Since its establishment, the practice base has witnessed more than 1000 students of class 2001-2001 from different majors to carry out field practice which lasted 2-3 weeks in Minjiang River system around Ya'an city.

\section{Strengthening Management, Supervising Quality and Constructing “1137” Practical Teaching Management plus Quality Monitoring Mode}

In order to ensure the quality of practical teaching, and social demands, educational resources, specialty characteristics and advantages, college resources and present situation of teachers and students are investigated and analyzed. Consequently, a "1137" management pattern, namely the practical teaching management and quality monitoring mode of "one goal, one main line, three phases and seven links" is constructed.

One goal: it centers on the training goal of applied and compound engineering talents, highlights the talents training mode featuring a combination of production, study and research, strengthens the practical teaching, and constantly improves the level of schooling.

One main line: it guarantees that the main cultivation line featuring a combination of production, study and research can run smoothly during students’ four years of university cultivation.

Three stages: firstly, it is made clear at the freshmen entrance stage that students shall have a clear goal and stable orientation; secondly, students in grade two and three shall give priority to curriculum experiment, practice and curriculum design and lay a solid foundation in their specialized study; thirdly, students in grade four: shall combine production, study and research, complete the transformation of professional theories and industrial production standard to the comprehensive results.

Seven links: 1) (professional ideological education) it makes clear the specialty orientation; 2) (specialty understanding and practice) it strengthens and stabilize students' thoughts about their specialty; 3) (curriculum experiment) it helps students master the methods and means of doing basic experiments and trains their action ability and basic skills; 4) (course practice), through preliminary combination of theory and practice it consolidates students' mastery of the basic theories; 5) (curriculum design) it promotes the cultivation and training of the basic ability to solve social practical problems with the application of specialized theories; 6) (training at practice base) it helps students participate in special training platform which combines production, study and research, trains students' comprehensive ability to analyze and solve problem and cultivates their ability to be a team player; 7) (graduation practice and graduation design) it makes the most of actual production project to establish graduation design topic, that is to say, "achievements shall be displayed to everyone openly".

\section{Construction Achievements}

Through years of intensive construction, the innovative talent training system for social demands has been built and perfected, and the cultivation of students' practical and innovative ability has also been strengthened. Further improvement and development have been achieved in aspects of talent training, laboratory construction and field practice, etc. Moreover, the overall strength has been enhanced and specialty features have become all the more obvious. All these can be confirmed as follows:

1) The majors became the key evaluation objects in during undergraduate teaching quality evaluation conducted by China's Ministry of Education in 2005. Shi Kebin from Xinjiang, professor of Agricultural University, firstly examined the teaching condition, faculty strength, laboratory construction and teachers' lectures, and then made a random sample of 10 undergraduates from water conservancy major of grade 2003 for professional skill test such as concrete slump test of mortar and soil mechanics shear test, and was greatly satisfied with the test results. Owing to the 
good performance during the assessment, the majors were rated as excellent and successfully passed the teaching quality evaluation by the Ministry of Education

2) Because of the distinctive advantages that focus on the students' science and technology innovation, students have won the national "Cup of Challenge" Science and Technology Competition and many other national and provincial awards. For instance, Wu Juan, an agricultural water conservancy engineering major of grade 2001, who hosted and participated in the project of “Sichuan Ya'an Bo'ai Ecological Food Co., Ltd”, won the gold award of Sichuan Province in the fourth National "Cup of Challenge" Collegiate Business Plan Competition and the silver medal of National Business Plan Competition. There were also seven students' graduation thesis which had been awarded the title of excellence; 16 papers were published in 4th, 5th, 6th, and 7th session of China's Water Forum; one paper was published in a key journal. Meanwhile, students had also participated in the compiling of five text books and three specialized works, which total more than 3 million words. Moreover, students had also got involved in the research and development of the rural water safety decision supporting system, water quality risk assessment system and field practice websites, etc. In 2009, some students of grade 2007-2008 won a national college student innovation experiment program and a college students' research interest cultivation project of Sichuan Agricultural University.

3) Due to their overall excellence, three students of grade 2003 named Yang Yuelin, Lin Sen, Li Xiaobo and Xu Bing of grade 2004 were been sent abroad to Sudan for the construction of Merowe hydropower station (this project is called "the three gorges project on the Nile" and is now in operation) along with the Morocco highway upon their employment in the fifth bureau of hydropower project in Chengdu. Additionally, quite a few other students passed the national and provincial civil servants tests. For example, Zhang Jiongjiong of grade 2005 passed the national civil servants test and was employed in China's Ocean and River Water Conservancy Ministry in 2009.

4) Students named Dai Xiaoping, Wu Juan, Ma Shiwu, Ao Ling from water conservancy major of grade 2001, Wang Haibo and Gao Yangyang from water conservancy major of grade 2003, Ren Huazhun, Chenyu from water conservancy major of grade 2004, Ye Jian, Yang Shangchuan from water conservancy major of grade 2005, and Students named Tan Yaosheng, Jiang Linlin, Tian Shuai, Li Changwen, Tang Ting, Zheng Jiao, Zheng Ji from water conservancy major of grade 2006 were either recommended or exempt from entrance test for a direct $\mathrm{PhD}$ study in those national key universities such as Tianjin University, Huazhong Science and Technology University, Sichuan University, Hehai University and Zhengzhou University. Dai Xiaoping is now studying in Japan. Owing to their outstanding performance in the postgraduate admission interview, they have been highly praised. Their scientific and technological innovation capability, their range of specialized knowledge and academic potential were also highly valued.

5) One-time employment rate of graduates of each year is more than $98 \%$ and the vast majority of graduates all have four to five job offers to choose from. The main employment organizations are Three Gorges Project Corporation, Gezhouba Group Company, the Fourth, Fifth, Seventh and Eighth Bureau of China's Hydropower Engineering, Bureau of Water Resources of each county and city in Sichuan province, etc. They mainly take the job concerning water conservancy, hydropower, civil engineering, railways, highways, nuclear power plants, high-speed rail, land and so on and work in

provincial capitals like Chengdu, Nanjing, Haikou, Wuhan, and Changsha, etc. Their main occupations are engineering and technical personnel (in design, construction and supervision), civil servants (in river basin management and water management in cities and counties) etc.

6) The major was rate as a distinctive specialty of Sichuan province in 2010.

\section{Conclusion}

Water conservancy is the lifeblood of "agriculture, rural areas and farmers", which is also an important matter concerning Chinese agriculture, rural development, farmers' life, economic and social development, and the security of flood control, water supply, food, economy, ecological situation as well as the whole nation. The No.1 Document issued by the Central Committee of the Communist Party of China in 2011 put forward the development direction and key tasks of water 
conservancy reform in the new period. It also raised new requirements for practical teaching reform of agricultural water conservancy majors in Sichuan Agricultural University. Research on practical teaching system of agricultural water conservancy engineering talents cultivation will further promote a sound and fast development of this major.

\section{Acknowledgment}

This paper is funded by Educational Reform Project (P09150) of Provincial Education Department, Provincial Specialty Construction Project (00508903), Educational Reform Project (00508901) of Sichuan Agricultural University and Research Team Project of Sichuan Agricultural University.

\section{References}

[1] Li Chunsheng, Gu Xiaoping, Guo Weidong etc. Teaching practice and thinking of the specialized course of water conservancy engineering general budget [J]. Journal of Shenyang Agricultural University (social science edition), 2006, 8(4): 674-676.

[2] Sun Nan, Liu Dong, Wang Qiuping. The teaching reform and practice in the course of civil engineering construction [J]. Journal of Economic Study, 2008, No. 6: 181-182.

[3] Huang Zhiquan, Liu Handong. Undergraduate teaching reform thoughts and practice with geotechnical and geological engineering major as an example [J]. Journal of North China Water Conservancy and Hydropower Institute (social science edition), 2007, 23 (1): 80-82.

[4] Wei Lidong, Jia Guoling. Zhang Zeguang. Construction of evaluation system of geographical practice teaching [J]. Journal of Hengshui College, 2008, 10 (1): 105-107.

[5] Run Yumin, Bai Jingfu. Research on cultivation standards for vocational talents of the water conservancy major [J]. Journal of Vocational Education Research, 2009 (6): 31-32.

[6] Wei Xinjun, Xu Changfeng. Research on the curriculum of web pages making of multimedia majors [J]. Journal of Information Science and Technology (science and technology education edition), 2006 (7):21.

[7] Wu Zhiliu. Analysis on the connotation of practical teaching in higher vocational and technical education [J]. Journal of Luohe Vocational and Technical College (comprehensive edition), 2006, 5 (4): 38 - 39.

[8] Lin Bing, Cheng Shu, Zeng Bo. The reform and practice on the teaching methods and teaching means in integrating work and learning in higher vocational colleges [J]. Journal of Guangdong Vocational and Technical College of Hydraulic and Electric Engineering, 2009, 7 (1): 19-22. 